\title{
When Mariko talks to Siegfried
}

\author{
- Experiences from a Japanese/German \\ Machine Translation Project -
}

\author{
Dietmar Rösner \\ Projekt SEMSYN, Institut fuir Informatik \\ Universität Stuttgart,Herdweg 51 \\ D-7000 Stuttgart 1 \\ West Germany
}

\begin{abstract}
In this paper we will report on our experiences from a $21 / 2$ year project that designed and implemented a prototypical Japanese to German translation system for titles of Japanese papers.

\section{Background}

An american study - published in Nature, 308 (1984) - evaluated cir. 9000 Japanese scientific papers. 75 percent of them are published exclusively in Japanese, only a 5 th of Japanese papers are currently evaluated from Western refereeing and information services. The main conclusion of the study was, that the general opinion all important Japanese stuff would be published in English is not true, at least for the applied sciences. From this background and from the Japanese success in a lot of fields of modern technologies stems a wider interest in having access to Japanese material and in having help to overcome the language barrier.
\end{abstract}

\section{TIT-1 =倩報技術とその来国教育への影橥}

Die Informationatechnologie und ihr EinfluB auf die Ausbildung in den USa.

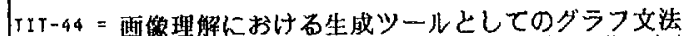

Die Graphranetik als Generierungs-Herkzeug bei verstehen von Bildern.

T1T-221=多重プロセッサによ石践水準グラフィック機能端末

Ein Terminal ait hochwertigen Graphik-Funktionen, das wit oinew mohrachen

Prozessor realistart wird.

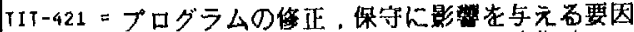

Faktoren zur Beoinflussung von Hartungen und Verbessarungen von Prograwean.

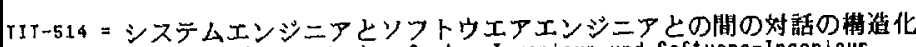
Dio struktur dos Dialogs zuischen System-Ingenieur und Softwaro-Ingeniour.

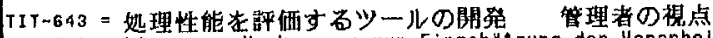

bie Entwicklung von Herkzougen zur Einschatzung der Vararbeltungslaistung. Der Standpunkt des Managers.

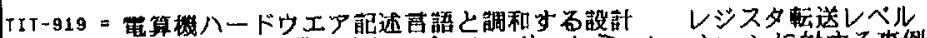
におけるビットスライス型マイクロブロセッサ・シミュレーションに奶す石事例 研究

Ein Enthurf, der auf aing Sprache zur Speziflkation von Computerharduare abgestimat wird. Die Fallatudio bel der Simulation von Mikro-prozeasoren von B|t-s|lce-Typ auf der Ebane der RegisterUbertragung.

**HORE**

I11. I Frow Japanese to German Via ATL.AS/II and SENSYN

\section{SEMSYN - a Japanese/German translation system}

The project SEMSYN-83 - SEMSYN is an acronym for SEM antic SYNthesis - has produced a system for the generation of German from semantic representations. The combination of this generator with the ATLAS/II-System of the Japanese cooperation partner FUJITSU may be seen as the first Japanese to German translation system.

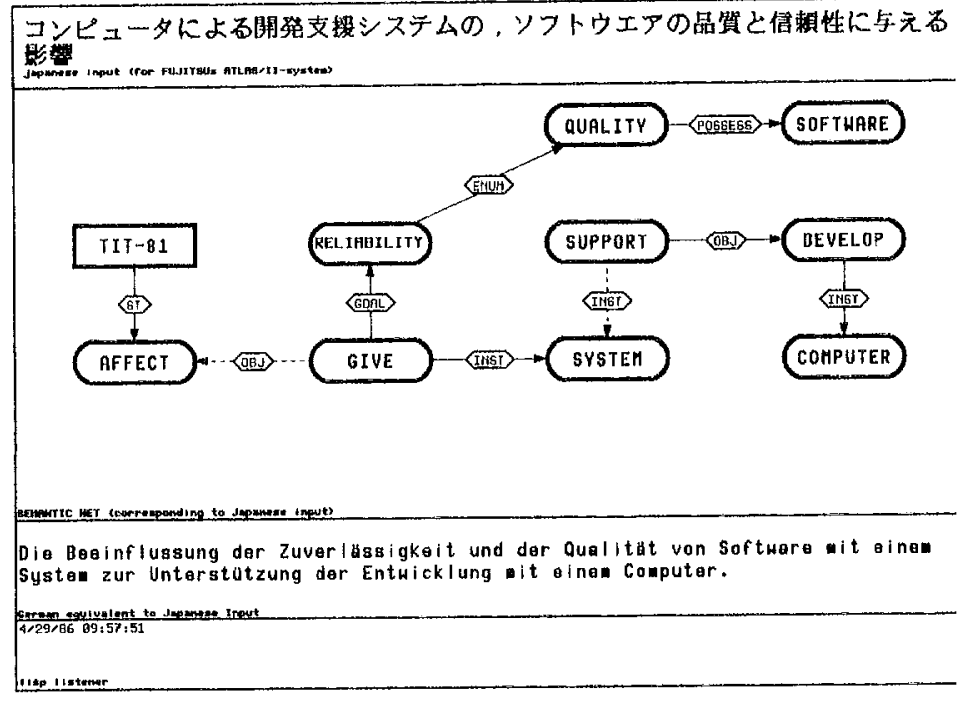

The analysis of the Japanese input - currently at most titles of scientific papers from the field of information technology - and its transformation into the semantic representation is the task of ATLAS/II. SEMSYN's part is to produce a correct and understandable German text for these semantic representations

\section{The overall design of the SEMSYN-System}

SEMSYN's generation from. FUJITSU's nets to German surface structures is done in three main steps.

The first step is to transform the semantic net delivered by FUJITSU into an expression of our own frame representation language - the so called IKBS-descriptions. IKBS stands for

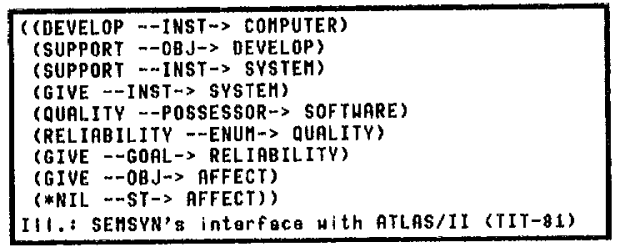

Instantiated Knowledge Base Schemata. This transformation does not only lead to a more structured representation, it helps as well to keep the generation modul somewhat independent from the special form of the FUJITSU interface. 
The second -- and probably most important - step is to decide in which way the content of the semantic representation should be uttered as German text. The output of this step is a functional description of the intended utterance in grammatical terms (IRS = Instantiated Realization Schema) The IRS description completely determines the German output. Its terminal elements are root forms of German words and their syntactic features.

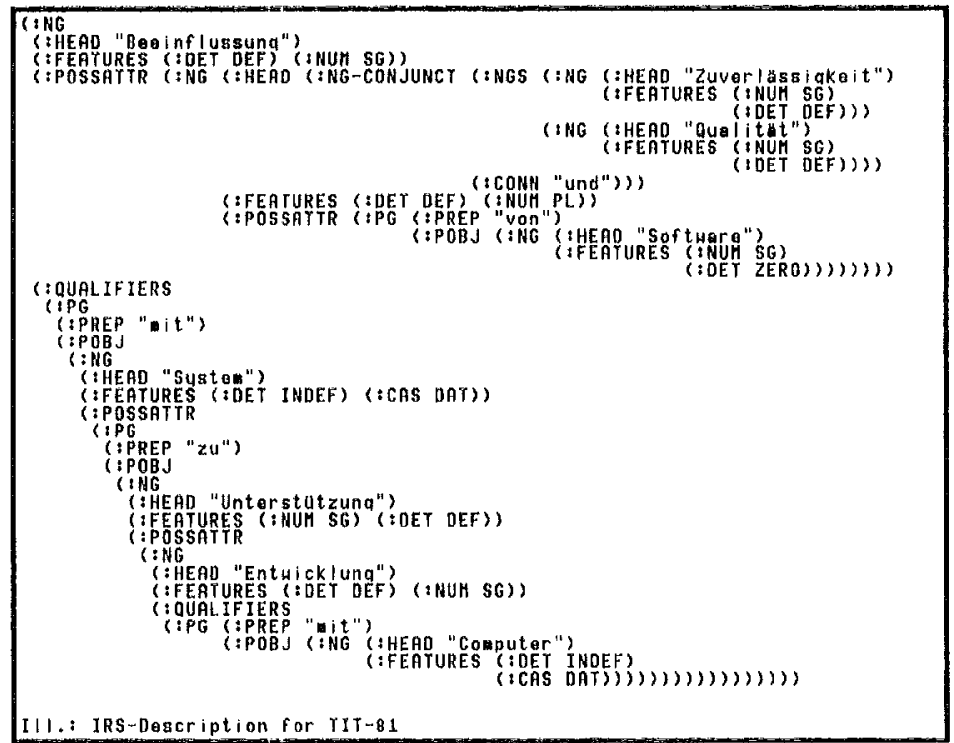

The third step - the generator-front-end SUTRA-S - takes the IRS description and produces a corresponding syntactically and morphologically correct German surface structure (Emele \& Momma, 1985). SUTRA-S is an extended reimplementation of the program SUTRA that has been developped by Busemann in the HAM-ANS project (Busemann, 1982).

\section{Generation from frame descriptions}

\subsection{The frame description language}

The formal definition of SEMSYN's frame representation is as follows

$$
\begin{aligned}
& <\text { IKBS-DFSCR }>:==\text { (A <FRAME-NAME>) } \\
& \text { (A <FRAME-NAME> } \\
& \text { WITI , <SLOTS\&LILLERS>) } \\
& (\text { THE <SLOT-NAME> FROM <IKBS-DESCR>) } \\
& \text { <SLOTS\&FILLERS }>:==((\langle\text { SLOT-NAME }>=\langle\text { IKBS-DESCR }>) \\
& \text {... }
\end{aligned}
$$

Conceptually we distinguish the following three main classes of frames:

1. Case schemata for verb concepts or actions (among these are all those frames that have case roles as slots).

2. Concept schemata for noun concepts or "picture producers"

3. Relation schemata - ENUMERATION, PURPOSE-, SCOPERelation etc.

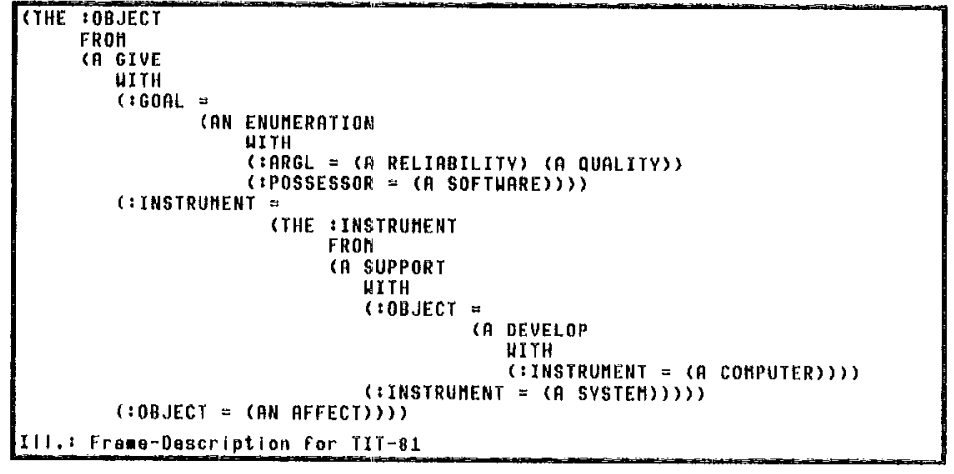

Within this scope the repertoire of the semantic represen tation includes:

\footnotetext{
- "classical" case roles a la Fillmore (agent, object, method, instrument, source, goal ,...)

- roles for the further specification of actions

(manner, place, time ...)

- roles for the further specification of concepts

(name, concern, specialize ...)

ways to quantify and attribute concepts

- modality (e.g not, possible ...)

- conjunctive and disjunctive ENUMERATION.
}

\subsection{Knowledge bases during generation}

SEMSYN's main generation phase may be viewed as communication between two knowledge bases: General knowledge about principal possibilities for realizing the semantic structures - the so called realization schemata - and specific knowledge mainly about diverse possibilities for lexicalization of semantic symbols. The latter is stored within the semantic to German dictionary SLEX (Rösner, 1986).

\subsection{Object-oriented implementation}

The general knowledge about possible realizations has been implemented using the FLAVOR system of the LISP machine The classes of the frame representation correspond to flavor classes. Realization schemata and the knowledge about the realization of roles are defined as flavor methods. This object-oriented architecture has shown to be verv flexible. It supported experimenting with the system and its step-bystep improvement.

\subsection{Realization schemata}

Frame descriptions as used in SEMSYN are recursive structures and so is - in general - the control structure in SEMSYN's generation. In other words: the same decisions have to be redone on each level of embedding. In embedded frames of course some decisions are already restricted by the context.

What will be the syntactic form of the text generated for such a frame? At least for case schemata we have as first alternative the choice between the realization types :CLAUSE and :NG (noun group). For semantic structures from titles we used as default to generate a noun group (a toplevel case schema was lexicalised as noun). Only in a few cases we had titles that had to be generated as questions like "What is a model of ...?" 
If the general syntactic form has been decided upon, there are more choices: a clause for example could be realized as an active or a passive clause. Within a noun group the attribute could be realized as a relative clause or in the form of a prepositional group.

\footnotetext{
:NG as ritlem-Dafault,

Dla Beainflusgung der Zuverlagsigkalt und der Qualitat von Softwara it ainea System zur Unterstatzung der Enthicklung it oinem Computer.

: HG with *PREFER-RELATIVE-CL.AUSES*:

Die Beainflussung der Zuverlassigkeit und der Quelitat von Softwere wit

oinew System, it dem die Entulcklung it oinam Computer unterstatzt Hird.

: CLAUSE in posaive voica:

Die Zuverlassigkeit und die qualitat von Softwara hird it ainam Systan zur Unterstutzung Her Entuicklung it oinew Couputer beginfluBt.

: GLAUSE with anonymous Agent:

Man beoinfluat die Zuverlagsigkait und die Quslitat von Softhare it ainew Syste zur Unterstutzung der Entuicklung it einen Couputer.

111.: Different Realisations for TIT-81
}

These decisions are done with respect to several factors One is the type of the actually filled roles. If a case schema for example has an :OBJECT, but no :AGENT, we prefer the passive construction in a clause realization. On the other hand stylistic preferences could be another factor. In the above case a preference could be to avoid passive, so we would take the realization schema "ACTIVE with an anonymus agent of 'man'"

In titles these preferences come from global switches. In real text they could come from the context

\subsection{Role realizations}

For frames without roles - the so called terminal structures - the realization is more or less the lexicalisation of the semantic symbol. After this, process control and the produced IRS structure is given back to the surrounding frame or the toplevel

If there are roles, there is some more work to be done Some fillers of roles are realized as distinct structures of their own (mostly noun groups). They could be uttered for themselves

Other roles only lead to changes in the IRS structure of their frame:

-decision about syntactic features: fillers of a :NUMBER role may e.g. lead to the pluralization of the noun group of the modified frame.

-creation of noun compounds as head of the actual nominal group: the filler of a :NAME role may become a prefix ("das SEMSYN-Projekt"). This holds as well for the terminal filler of a :SPECIALIZE role (variant: realization as an adjective). $A$ negative :MODALITY could - in a noun group realization - lead to the prefix "Nicht-".

For those frames that have roles with realizations of their own this procedure recursively repeats for the frame descriptions of the fillers of those slots.

For realized role fillers it has to be decided how their IRSstructure shall be integrated in the overall structure (mostly as prepositional group) and which syntactic features could additionally be inferred.

\section{Inferring of missing information}

SEMSYN's generation modul starts from a semantic representation that was designed to be language independent. For the primitives used - especially for the semantic relations expressed by the arcs in the semantic net - this may be true.

On the other hand the data delivered to us by FUJITSU are not really universal representations. The fact that the semantic nets are derived from Japanese is recognizable if one looks at the information that is not explicitly represented.

In Japanese number or definiteness of nouns or time of verbs normally is not expressed - correspondingly our data do not have semantic correlates for these features lexcept in the rare case when they have been expressed in the Japanese original). The Japanese reader infers the missing information from the context. In titles there is no such context available. For correct and acceptable German on the other hand we need determiners and our nouns need a number. Therefore we had to develop heuristics to reconstruct this information.

Some examples of such heuristics

- a nominalized case frame has to be realized with definite article in singular ("Die Generierung natürlicher Sprache").

- the :OBJECT role of a nominalized case frame should be realized indefinite and plural ("Die Generierung von Titeln") except in cases with an exception information in SLEX ("Die Wartung von Software").

- concepts that have a :NAME role will be realized definite and singular ("Die Fourier-Transformation")

If no heuristic is applicable and if no SLEX information is found we use as title defaults 'indefinite' and 'singular' ("Ein Verfahren").

\section{Concluding remarks}

Our current concern is to broaden the applicability of SEMSYN's generator for German: On the one hand we are experimenting with the generation of full texts (e.g. newspaper stories). on the other hand we are extending the repertoire of feasible semantic structures that may serve as input for the generator.

Acknowledgement:

SEMSYN-83 has been funded by the West German Ministry for Research and Technology (BMFI) from July 1983 till February 1986. Special thanks to all the colleagues that collaborated - for shorter or longer periods - within this project: Kenji Hanakata, Joachim Laubsch, Arek Lesniewki and Shoichi Yokovama.

References

Busemann, S. (1982) "Probleme der automatischen Generierung deutscher Sprache", HAM-ANS Memo 8 Universität Hamburg

Emele, M. \& S. Momma (1985) "SUTRA-S - Erweiterungen eines Generator-Front-Ends fuer das SEMSYN-Projekt", Studienarbeit, Inst. f. Informatik, Univ. Stuttgart

Laubsch,J., Rösner,D., Hanakata,K., Lesniewski,A. (1984) "Language Generation from Conceptual Structure: Synthesis of German in a Japanese/German MT Project", in: COLING-84 Proceedings, Stanford

Rösner, D. (1986) "SEMSYN - Wissensquellen und Strategien bei der Generierung von Deutsch aus einer semantischen Repräsentation", in: Batori \& Weber (Eds.) Neue Ansätze in Maschineller Sprachübersetzung: Wissensrepräsentation und Textbezug", Niemeyer Verlag. Tübingen

Uchida, H. \& K. Sugiyama (1980) "A machine translation system from Japanese into English based on conceptual structure ", in: COL.ING-80, Proceedings, Tokyo, S. 455-462 